\title{
Pro-IGF2-induced hypoglycaemia associated with hepatocellular carcinoma
}

\section{S A A van den Berg1, + and C G Krol2}

Departments of ${ }^{1}$ Clinical Chemistry and Hematology and 2 Internal Medicine, Amphia Hospital, Breda, The Netherlands

${ }^{\dagger}$ (S A A van den Berg is now at Department of Clinical Chemistry, Erasmus Medical Center, Rotterdam, The Netherlands)
Correspondence should be addressed to $S$ A A van den Berg Email

s.a.a.vandenberg@ erasmusmc.nl

\section{Summary}

We present a patient (87 years, female) who was admitted to the emergency department because of loss of consciousness. Previous medical history included advanced-stage hepatocellular carcinoma and associated weight loss. She was found on the ground in an unresponsive state by her daughter and was determined to be hypoglycaemic. Upon bolus administration of $100 \mathrm{~mL}$ intravenous glucose $(10 \%)$, glucose levels increased to $2.9 \mathrm{mmol} / \mathrm{L}$ and the patient regained full consciousness. She was admitted to the hospital for further examination, and treatment and continuous intravenous glucose infusion was initiated. As the patient was known to suffer from advanced-stage hepatocellular carcinoma, tumour-associated hypoglycaemia was suspected. Insulin, c-peptide and IGF1 concentrations were indeed low, cortisol concentration was high and IGF2 and Pro-IGF2 were borderline low and borderline high normal respectively. IGF2:IGF1 ratio was 23 , confirming the diagnosis of non-islet cell tumour hypoglycaemia. During the initial phase of treatment, euglycaemia was maintained by continuous variable glucose infusion ( $5 \%$, varying between 1 and $2 \mathrm{~L} / 24 \mathrm{~h})$, and the patient was advised to eat small snacks throughout the day. After euglycaemia was established and the diagnosis was confirmed, prednisolone was started ( $30 \mathrm{mg}, 1 \mathrm{dd}$ ) and glucose infusions were halted. Under prednisolone treatment, glucose levels were slightly increased and no further hypoglycaemic episodes occurred. At her request, no surgery was performed. After 19 days, the patient was discharged to a hospice and died 3 weeks later.

\section{Learning points:}

- Hepatocellular carcinoma may be associated with non-islet cell tumour hypoglycaemia (NICTH).

- NICTH-induced hypoglycaemia is associated with low insulin and IGF1.

- Measurement of IGF2 only (without measurement of Pro-IGF2 and IGF1) may be insufficient to prove NICTH.

\section{Background}

Non-islet cell tumour hypoglycaemia (NICTH) is a rare complication of malignancy. Although the exact incidence of NICTH is unknown, it is estimated to be about $1 / 4$ th of the incidence of insulinoma, but is probably underestimated because of occult disease (1).

NICTH is associated with several abnormalities in biochemical and endocrinological blood tests.
For example, glucose, non-esterified fatty acids, insulin, c-peptide, growth hormone, IGF1, IGFBP3 and acid-labile substrate are commonly low, whereas Pro-IGF2 and/or IGF2 and IGFBP6 are elevated (2).

It has also been shown that an elevated concentration of IGF2 may be predictive and/or prognostic for other tumour types, such as colorectal, colon, prostate and 
head and neck cancer (2). Furthermore, the ratio between IGF2 and its homolog IGF1 is useful in the diagnosis and monitoring of NICTH.

The elevated concentrations of Pro-IGF2 and IGF2 are the result of overexpression of the IGF2 gene in the tumour, resulting in an overproduction of incompletely processed precursors of IGF2 (Pro-IGF2 or big IGF2) (3). Pro-IGF2 and IGF2 augment peripheral glucose consumption and repress endogenous glucose, resulting in hypoglycaemia (4). At diagnosis, serum level of total IGF2 may be normal, but both the ratios of Pro-IGF2:IGF2 and IGF2:IGF1 are often found elevated in cases of NICTH (3). A ratio of $>10$ is generally considered indicative for the diagnosis of NICTH (2).

\section{Case presentation}

The patient described in this case report was known to suffer from hepatocellular carcinoma, diagnosed five years before admission and for which she did not wish to receive treatment. There was no history of hypoglycaemic episodes or diabetes. At the time of presentation, the patient was found on the ground in an unresponsive state by her daughter. At first, her general practitioner suspected a cerebrovascular accident, but glucose measurement revealed that she was hypoglycaemic. After a glucose bolus ( $100 \mathrm{~mL}$ of $10 \%$ glucose), glucose concentration increased to $2.9 \mathrm{mmol} / \mathrm{L}$, after which she regained full consciousness. Upon admission to the hospital, glucose concentration was again low $(1.6 \mathrm{mmol} / \mathrm{L})$ and a continuous glucose infusion $(5 \%, 2 \mathrm{~L} / 24 \mathrm{~h})$ was started.

\section{Investigation}

Glucose was measured and found to be low by the patient's general practitioner, the exact concentration not known to the authors. At the time of admission, glucose concentration had decreased to $1.6 \mathrm{mmol} / \mathrm{L}$ and a continuous glucose infusion was started. At various timepoints during treatment, glucose was measured and continuous glucose infusion rate was titrated to maintain euglycaemia.

To determine the cause of the hypoglycaemia, cortisol, insulin and c-peptide levels were measured. Cortisol concentration was high $(1.03 \mu \mathrm{mol} / \mathrm{L}$, normal: $0.07-0.69 \mu \mathrm{mol} / \mathrm{L})$, excluding hypocortisolism, whereas insulin and c-peptide concentrations were low $(<0.2 \mathrm{U} / \mathrm{L}$, normal: $6.0-29.0 \mathrm{U} / \mathrm{L}$ and $0.05 \mathrm{pmol} / \mathrm{mL}$, normal: $0.25-$ $0.90 \mathrm{pmol} / \mathrm{mL}$ respectively), indicating hypoinsulinaemic hypoglycaemia. As the patient was previously diagnosed with advanced hepatocellular carcinoma, NICTH was expected. To establish the diagnosis, IGF1, IGF2 and Pro-IGF2 were measured. IGF1 concentration was low $(<1.6 \mathrm{nmol} / \mathrm{L}(12 \mathrm{ng} / \mathrm{mL})$, normal: 6.8 (52)$29.2(223) \mathrm{nmol} / \mathrm{L}(\mathrm{ng} / \mathrm{mL}))$. IGF2 concentration was low/normal (280 ng/mL, normal: 280-610 ng/mL), whereas Pro-IGF2 was high/normal $(27 \mu \mathrm{g} / \mathrm{L}$, normal: $9.0-27.0 \mu \mathrm{g} / \mathrm{L})$. The ratio of IGF2:IGF1 was $23(>10)$, confirming the diagnosis of NICTH.

\section{Treatment}

During admission, hypoglycaemia was corrected by continuous glucose infusion, as recommended (3), and the patient was instructed to consume carbohydrate-rich snacks throughout the day. Our patient declined treatment for her hepatocellular carcinoma, the only definitive treatment option for NICTH. Prednisolone $(30 \mathrm{mg}, 1 \mathrm{dd}$ orally) was started, and glucose infusions were reduced and halted. Patient developed mild hyperglycaemia and no further hypoglycaemic episodes occurred.

\section{Outcome and follow-up}

Due to her advanced-stage hepatocellular carcinoma and her wish not to be treated, our patient was discharged to a hospice where she died three weeks later.

\section{Discussion}

Non-islet cell tumour hypoglycaemia is a rare complication of malignancy and can be seen in for example in hepatocellular carcinoma (HCC). Here, we present a patient with advanced-stage HCC, presenting with severe hypoinsulinaemic hypoglycaemia due to increased tumour-mediated IGF-2 synthesis.

The increased bioavailability of IGF- 2 and Pro-IGF2 has pleotropic effects on glucose metabolism mediated through the insulin-IGF-1 family of receptors, causing hypoglycaemia (5). As these receptors are highly expressed in several insulin-responsive organs, hypoglycaemia occurs due to various mechanisms, including repression of ketogenesis, hepatic glucose production and increased muscular glucose utilisation. This effect is further aggravated due to higher bioavailability of IGF2 hormone. Pro-IGF2 has decreased potency to form ternary complexes (6), and suppression of growth hormone production results in decreased levels of IGF1, IGFBP3 and acid-labile substrate (6). 
Treatment is aimed at achieving and maintaining euglycaemia. Definitive treatment is achieved by removal of the tumour. Otherwise, hypoglycaemia can be controlled by reduction of tumour size by resection, chemotherapy, embolisation or radiotherapy (7). Dietary measures include regular administration of glucose tablets or other carbohydrates. Corticosteroids are the mainstay of treatment and decrease the levels of pro and big IGF2 by converting pre-pro IGF into IGF2 and re-establishing normal IGF-to-IGFBP ratio (8). Other medical treatment options included diazoxide, octreotide, glucose or glucagon infusions and recombinant growth hormone (7).

In conclusion, NICTH is a rare complication of malignancy and is caused by increased bioavailability of IGF2. It should be suspected in patients with unexplained hypoinsulinaemic hypoglycaemia, especially in the presence of a known malignancy.

Patient's perspective

Unfortunately, due to the loss of follow-up of our patient, we were not able to inquire about her perspective.

Declaration of interest

The authors declare that there is no conflict of interest that could be perceived as prejudicing the impartiality of the research reported.

\section{Funding}

This research did not receive any specific grant from any funding agency in the public, commercial or not-for-profit sector.
Patient consent

After admission to the hospice, patient died within 3 weeks. Informed consent was not sought from the patient or her family.

Author contribution statement

S A A van den Berg was involved as a laboratory consultant and wrote the manuscript. C G Krol is the physician who was responsible for the patient and wrote the manuscript.

\section{References}

1 Marks V \& Teale JD 1998 Tumours producing hypoglycaemia. Endocrine-Related Cancer 5 111-129. (doi:10.1677/erc.0.0050111)

2 Livingstone C 2013 IGF2 and cancer. Endocrine-Related Cancer 20 321-339. (doi:10.1530/ERC-13-0231)

3 Iglesias P \& Diez JJ 2014 Management of endocrine disease: a clinical update on tumor-induced hypoglycemia. European Journal of Endocrinology 170 R147-R157. (doi:10.1530/EJE-13-1012)

4 Cryer PE, Axelrod L, Grossman AB, Heller SR, Montori VM, Seaquist ER \& Service FJ 2009 Evaluation and management of adult hypoglycemic disorders: an endocrine society clinical practice guideline. Journal of Clinical Endocrinology and Metabolism 94 709-728. (doi:10.1210/jc.2008-1410)

5 Dynkevich Y, Rother KI, Whitford I, Qureshi S, Galiveeti S, Szulc AL, Danoff A, Breen TL, Kaviani N, Shanik MH, et al. 2013 Tumors, IGF-2, and hypoglycemia: insights from the clinic, the laboratory, and the historical archive. Endocrine Reviews 34 798-826. (doi:10.1210/er.2012-1033)

6 Bond JJ, Meka S \& Baxter RC 2000 Binding characteristics of proinsulin-like growth factor-II from cancer patients: binary and ternary complex formation with IGF binding proteins-1 to -6. Journal of Endocrinology 165 253-260. (doi:10.1677/joe.0.1650253)

7 Huang J \& Chang P 2015 Refractory hypoglycemia controlled by systemic chemotherapy with advanced hepatocellular carcinoma: a case report. Oncology Letters 11 898-900. (doi:10.3892/ol.2015.3915)

8 Teale JD \& Marks V 1998 Glucocorticoid therapy suppresses abnormal secretion of big IGF-II by non-islet cell tumours inducing hypoglycaemia (NICTH). Clinical Endocrinology 49 491-498. (doi:10.1046/j.1365-2265.1998.00564.x)

Received in final form 27 March 2017

Accepted 31 March 2017 